\section{Irish Smokers with Rheumatoid Arthritis Suffer More Than Their Nonsmoking Counterparts}

\section{To the Editor:}

We have noted a 1.5 relative risk (RR) of people with inflammatory arthritis failing at least one anti-tumor necrosis factor (TNF) therapy and a 1.6 RR of failing disease-modifying antirheumatic drug (DMARD) therapy if they are "ever-smokers" (current or past smokers). This is based on a prospective longitudinal analysis of 793 patients, of whom $102(13 \%)$ were deemed to have failed an anti-TNF drug due to inefficacy and 452 patients who previously failed a conventional DMARD for whom smoking data were available. Sixty percent of the database cohort were ever-smokers whereas the remaining $40 \%$ never smoked tobacco. It has recently been proposed ${ }^{1}$ that exposure to tobacco smoke reduced the efficacy of anti-TNF therapy in patients with rheumatoid arthritis (RA). Mattey, et al noted higher Disease Activity Scores (DAS) in ever-smokers compared with never-smokers despite the use of anti-TNF therapy, and therefore inferred that tobacco smoking, current or past, impairs the therapeutic action of these advanced biologic agents. They found that the higher DAS scores among ever-smokers were due to patient global scores on visual analog scales (VAS) and tender joint counts, yet found no differences in levels of inflammatory markers, swollen joint counts, and physician global VAS between ever- and never-smokers. These findings suggest a greater incidence of periarticular pain syndromes among RA ever-smokers than RA never-smokers, rather than proving a greater incidence of active synovitis despite anti-TNF therapy in the ever-smoking RA group. However, reflecting upon our own database findings, ever-smokers had a marginally higher mean swollen joint count than never-smokers at both 3 and 12 months while also having higher tender joint counts and overall DAS scores (Table 1).

Ever-smoking patients with fibromyalgia suffer more pain than never-smoking patients with fibromyalgia. A large robust population-based German study with almost 7000 participants showed that people who smoked had a 3.1-fold RR (95\% CI 1.8-5.3) of using analgesics daily, indicating a lower pain threshold among ever-smokers compared to neversmokers $^{2}$. The mechanism of this enhanced nociception is unclear and is the subject of much speculation. Tobacco smoke is composed of an estimated 4000 chemical constituents. It would follow that at least one of these compounds results in greater nociception. Of these, about 400 have been measured or estimated in mainstream and sidestream smoke. Of the 400 , significant toxicology data exist for fewer than 100. It will therefore be challenging to discover which of the compounds of inhaled tobacco smoke may exert this noxious effect. Nicotine, tar, and carbon monoxide are among the 3 better-known inhaled by-products of tobacco smoke. Of these, nicotine is known to have an analgesic effect via stimulation of both peripheral and central nicotinic receptors ${ }^{3}$ and has been shown to attenuate the onset of collagen-induced arthritis in rodents ${ }^{4}$, yet considering the

Table 1. Smoking status compared to disease activity scores (DAS) and tender joint counts (TJC) and swollen joint counts (SJC) after 3 and 12 months of anti-TNF therapy.

\begin{tabular}{lcccccc}
\hline & \multicolumn{3}{c}{ At 3 Months } & \multicolumn{3}{c}{ At 12 Months } \\
& DAS & TJC & SJC & DAS & TJC & SJC \\
\hline Current smokers & 3.42 & 3.96 & 4.27 & 3.04 & 3.40 & 2.97 \\
Ex-smokers & 3.26 & 3.37 & 3.51 & 3.09 & 3.28 & 2.62 \\
Never-smokers & 3.26 & 3.12 & 3.55 & 2.8 & 2.39 & 2 \\
\hline
\end{tabular}

harmful effect of pure nicotine on an individual's cardiovascular risk profile it cannot be administered as an analgesic. Studies are under way to find a harmless stimulator of acetylcholine nicotinic sensory receptors ${ }^{5}$. It is known that smoking tobacco is detrimental to pulmonary and cardiovascular health, among other effects. One might therefore assume an additive effect of an inflammatory arthritis and tobacco smoke exposure on the acceleration of arterial stiffness, endothelial dysfunction, and atheroma formation. Experience has taught us that many patients consider smoking cigarettes to be a respite from their suffering, but it is clear that the contrary is true and patients should be so advised in the interest of both their health and sense of well-being.

Smokers with RA do not have a more erosive disease, yet have a greater incidence of rheumatoid nodules ${ }^{6,7}$. This would again suggest that smoking does not result in worse synovitis, yet immune activation is persistent. The questions remain: Are nociceptors intrinsically more readily discharged or centrally perceived in smokers versus nonsmokers? Does a subclinical inflammatory arthritis persist in smokers despite the absence of objective evidence of inflammation? Is a noninflammatory immune reaction responsible for the enhanced pain perception of people who smoke?

LEONARD C. HARTY, MRCPI, Clinical Fellow in Rheumatology; DOUGLAS J. VEALE, MD, Consultant Rheumatologist, Professor of Translational Medical Research, St. Vincent's University Hospital, Elm Park, Dublin 4, Ireland. Address correspondence to Dr. Harty;

E-mail: lenharty@yahoo.com

\section{REFERENCES}

1. Mattey DL, Brownfield A, Dawes PT. Relationship between pack-year history of smoking and response to tumor necrosis factor antagonists in patients with rheumatoid arthritis. J Rheumatol 2009;36:1180-7.

2. John U, Alte D, Hanke M, Meyer C, Volzke H, Schumann A. Tobacco smoking in relation to analgesic drug use in a national adult population sample. Drug Alcohol Depend 2006;85:49-55.

3. Furst Z. Central and peripheral mechanisms in antinociception current and future perspectives. Neuropsychopharmacol Hung 2008;10:127-30.

4. van Maanen MA, Lebre MC, van der Poll, LaRosa GJ, Elbaum D, Vervoordeldonk MJ, et al. Stimulation of nicotinic acetylcholine receptors attenuates collagen-induced arthritis in mice. Arthritis Rheum 2009;60:114-22.

5. D'Hoedt D, Bertrand D. Nicotinic acetylcholine receptors: an overview on drug discovery. Expert Opin Ther Targets 2009;13:395-411.

6. Finckh A, Dehler S, Costenbader KH, Gabay C; Swiss Clinical Quality Management Project for RA. Cigarette smoking and radiographic progression in rheumatoid arthritis. Ann Rheum Dis 2007;66:1066-71

7. Mikuls TR, Hughes LB, Westfall AO, Holers VM, Parrish L, van der Heijde D, et al. Cigarette smoking, disease severity and autoantibody expression in African Americans with recent-onset rheumatoid arthritis. Ann Rheum Dis 2008;67:1529-34.

J Rheumatol 2010;37:5; doi:10.3899/jrheum.091403 